\title{
Analysis of Internal Friction Angle and Cohesion Value for Road Base Materials in a Specified Gradation
}

\author{
Grawira Ganjur Giwangkara ${ }^{1}$, Azman Mohamed $^{1 *}$, Hasanan Md.Nor ${ }^{1}$, Nur Hafizah A. \\ Khalid $^{1}$, and Rachmat Mudiyono ${ }^{2}$ \\ ${ }^{I}$ School of Civil Engineering, Faculty of Engineering, Universiti Teknologi Malaysia, 81310 Skudai, \\ Johor, Malaysia \\ ${ }^{2}$ Civil Engineering, Sultan Agung Islamic University Semarang, Indonesia \\ *Corresponding author: azmanmohamed.kl@utm.my
}

(Received: June 22 $2^{\text {nd }}, 2020$ Year ; Revised: October $1^{\text {st }} 2020$; Accepted: October $14^{\text {th }} 2020$ )

\begin{abstract}
Internal friction angle $(\varphi)$ is one of the important parameter in a foundation engineering, especially in the stress distribution event. The higher value of the internal friction angle shows the higher of the material can withstand the lateral force. Cohesion factor (c) is also an integral part of the shear strength for the foundation material. In the granular soil such as sand or non-cohesive material, including aggregate, cohesion value usually assumed as zero, although some cohesion factor may be applied. In this research, two different materials were tested for their shear strength. The materials were Natural Crushed Aggregate (NCA) and Recycled Concrete Aggregate (RCA). Each material was also tested under two different circumstances. First, the materials were tested in a small-scale direct shear (SSDS) test with the maximum material size of $0.425 \mathrm{~mm}$ and $2.0 \mathrm{~mm}$. Secondly, the materials were tested in a large-scale direct shear (LSDS) test with the graded size of aggregate according to road base layer specification. The SSDS showed the internal friction angle of NCA and RCA varies from 26.20 to 29.82 degrees. Whereas the LSDS showed the internal friction angle of NCA and RCA are 44.90 and 29.16 respectively. Both of SSDS and LSDS also showed the cohesion value of NCA and RCA.
\end{abstract}

Keywords: road base; internal friction angle; cohesion

\section{Introduction}

Nowadays, road pavements are getting advanced as the demand for a high-quality road is always rising. Some of the requirements for road pavement are having a good strength to distribute the stresses due to the working loads, provide the adequate friction to prevent a vehicle from skidding, provide a smooth surface for comfortable driving, and a long life design with low maintenance cost [1]. The stresses that work on the road surface must be well distributed until the subgrade layer. Road pavement with well-distributed stress will have a longer service life which will impact on the cost maintenance. Road pavement is constructed from various layers and materials. The materials for road pavement are divided into two general classes, those for flexible pavement and those for rigid pavement [2]. Flexible pavement, or known as asphalt pavement, has a layer which acts as a foundation directly under the asphalt layer. That layer is called as a road base layer or base course layer. Road base layer is constructed from crushed stoned, crushed slag, sand, or combination of these materials. Road base layer sometimes also treated to achieve greater performance in distributing the working load.

As a direct foundation under the surfacing pavement, road base layer use the grain-to-grain action 
to transfer the working load into a wider area [3]. The grain-to-grain action relies on the macro friction of the aggregate. In this case, the internal friction angle plays an important role as a parameter for stress distribution. Cohesion factor also being an indicator for the shear strength although its value usually considered as zero for granular soils such as aggregate. Many kinds of research have been conducted related to the internal friction angle and cohesion for granular soils but it is reminded that the results were affected by the material type, size and gradation, water content, crushing value, and any other factors that may apply. Especially for materials from demolition waste such as the RCA which will have a very large range for its shear strength [4].

Shear strength is the integral parts of the stress distribution event which the internal friction angle and the cohesion are the main parameters. The internal friction angle value generally listed in an interval value for some known materials and certain sizes. Road base layer has a various size of aggregate that cannot follow the known materials list. Not to mention for the newly applied material for the road base layer. Aggregate also usually stated as a non-cohesive soil which makes the cohesion value is assumed as zero. This situation makes the road base layer has an arguably shear strength according to its construction material.

The objectives of this research were to determine the internal friction angle and cohesion by using the small-scale direct shear (SSDS) test and the large-scale direct shear (LSDS) test. The LSDS test was conducted to gain the real internal friction angle and the cohesion value for the road base materials. The road base materials were constructed from natural crushed aggregate (NCA) and recycled concrete aggregate (RCA) in various size and compacted to represent the actual road base layer.

\section{Road Base in Road Construction}

Road base is a layer between the sub-base and surfacing layer in flexible pavement. Road base layer is generally the main structural layer for pavement as this layer bear the stresses from the wheel load on the surfacing layer [5]. When the vehicles move on the pavement surface, a load pulse is applied and creates stresses throughout the pavement layers. The materials for road base must fulfil the specified requirements according to the place where the road is constructed. According to Vinod B.R., aggregate as a prime material for road pavement must be strong, hard, tough, and durable [6]. Aggregate strength is the main factor for road base material as it will bear the stresses from the traffic load [7]. In a country such as Malaysia, the required physical properties for road base materials have been stated in Malaysian Standard Specification for Road Works Section 4 (JKR/SPJ/2008-S4), including the gradation limits [8].

Size and gradation for road base material may differ from one country to another. In this experiment, the size and gradation for road base material refer to the JKR/SPJ/2008-S4 which also based on the BS 1377. As well as any other specification for aggregate gradation, the limits for road base material in JKR/SPJ/2008-S4 also being given as seen in Table 1.

Table 1. Size and Gradation for Road Base Material

\begin{tabular}{cc}
\hline Sieve Size (mm) & Percentage Passing by Weight (\%) \\
\hline 50.0 & 100 \\
37.5 & $85-100$ \\
28.0 & $70-100$ \\
20.0 & $60-90$ \\
10.0 & $40-65$ \\
5.0 & $30-55$ \\
2.0 & $20-40$ \\
0.425 & $10-25$ \\
0.075 & $2-10$ \\
\hline
\end{tabular}




\section{Grawira Ganjur Giwangkara, Azman Mohamed, Hasanan Md.Nor, Nur Hafizah A. Khalid, and Rachmat Mudiyono}

\section{Shear Strength}

Shear strength is commonly described as the maximum internal resistance of a material to withstand the applied shearing force. Many factors may affect the shear strength such as material properties, initial condition, particle arrangement, loading conditions, etc. It is very difficult to obtain the accurate value of shear strength in a natural condition as the laboratory experiment use the recreated or remoulded sample [9]. There are two distinct parameters for shear strength based on Mohr-Coulomb failure criterion, namely the internal friction angle $(\varphi)$ and cohesion value (c). See Fig. 1. The internal friction angle represents the frictional resistance between material particles, whereas cohesion value represents the internal forces that bond the soil particles together [10]. Both of the internal friction angle and cohesion can be obtained from the direct shear test or triaxial shear test.

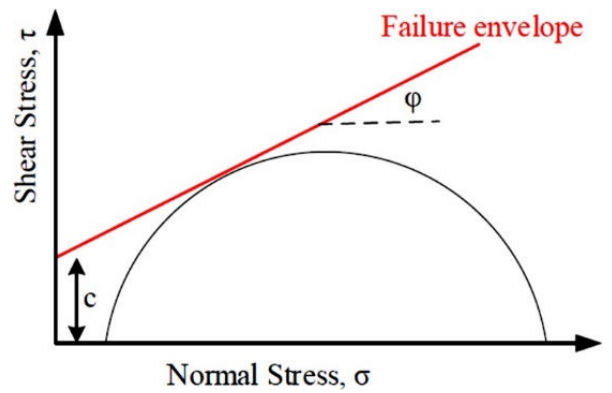

Fig. 1. Mohr-Coulomb chart on shear strength

The Mohr-Coulomb theory states that the shear strength $(\tau)$ is dependent on the normal stress $(\sigma)$, internal friction angle $(\varphi)$, and cohesion (c) as shown in Eq. (1).

$$
\tau=\mathrm{c}+(\sigma . \operatorname{Tan} \varphi)
$$

Aggregate is considered as a granular soil which means relatively has a little cohesion or mostly assumed as zero [5]. Therefore, the main source of shear strength for aggregate in gradation primarily comes from the internal friction angle. One that must be considered is the cohesion value may come very different between the NCA and RCA because of their natural state. Cohesion in NCA usually associated with the content of silt and clay, whereas in RCA the presence of adhered cement paste or any other additional substances may promote bonding between particles [10].

\section{Samples and Methodology}

This research was conducting two types of direct shear test with all referred to BS 1377-7:1990. First, the small-scale direct shear (SSDS) test which also known as shear box test for aggregate samples with a maximum size of 0.425 and $2.0 \mathrm{~mm}$. All materials for the SSDS test were in dry and loose condition. Second, the large-scale direct shear (LSDS) test for the aggregate in a specified gradation according to JKR/SPJ/2008-S4. All samples are as stated in Table 2. The principle of the direct shear test is the resistance offered by the material as it slides on the other and measured for its displacement [11].

There were three samples (three normal forces) for each sample type with a new sample foreach normal force. Failure will occur when the shearing resistance reaches the maximum value which the material can sustain. Three loads were applied to the SSDS test, namely $1 \mathrm{~kg}, 2 \mathrm{~kg}$, and $4 \mathrm{~kg}$. Those loads represent normal forces of $0.104 \mathrm{kN}, 0.202 \mathrm{kN}$, and $0.398 \mathrm{kN}$ as the shear box test has the eccentricity from its load handlebar. The size of the shear box was $60 \mathrm{~mm} \times 60 \mathrm{~mm}$ with an inner thickness of $20 \mathrm{~mm}$. Thus, the maximum size of the SSDS was $2.0 \mathrm{~mm}$ as in BS 13771:2016 stated that the maximum size is $\mathrm{H} / 10$ where $\mathrm{H}$ is the height of the specimen [12]. The apparatus for SSDS test as seen in Fig. 2 was connected to a computer and processed directly 
from its software.

Table 2. Size and Gradation for Road Base Material

\begin{tabular}{|c|c|c|c|c|}
\hline No & Sample Type & Test Type & $\begin{array}{c}\text { Moisture Content } \\
(\%)\end{array}$ & $\begin{array}{c}\text { Avg. Dry } \\
\text { Density }\left(\mathrm{kg} / \mathrm{m}^{3}\right) \\
\end{array}$ \\
\hline 1 & NCA $0.425 \mathrm{~mm}$ & SSDS & 0.00 & 1576 \\
\hline 2 & RCA $0.425 \mathrm{~mm}$ & SSDS & 0.00 & 1570 \\
\hline 3 & NCA $2.0 \mathrm{~mm}$ & SSDS & 0.00 & 1453 \\
\hline 4 & RCA $2.0 \mathrm{~mm}$ & SSDS & 0.00 & 1323 \\
\hline 5 & NCA in gradation & LSDS & 8.56 & 2031 \\
\hline 6 & RCA in gradation & LSDS & 938 & 1854 \\
\hline
\end{tabular}

For the LSDS test, the normal forces were $5 \mathrm{kN}, 10 \mathrm{kN}$, and $20 \mathrm{kN}$ and the size of the shear box was $200 \mathrm{~mm} \times 200 \mathrm{~mm}$ with $195 \mathrm{~mm}$ of inner thickness. All samples for the LSDS test were compacted into $95 \%$ of MDD. From previous research, NCA and RCA for this test have the MDD for $2,138 \mathrm{~kg} / \mathrm{m} 3$ and $1,952 \mathrm{~kg} / \mathrm{m} 3$ respectively [13]. The LSDS test also in a drained condition where the water pore pressure was not considered. All samples in the LSDS test were sheared into a minimum of $20 \mathrm{~mm}$ of displacement as it was the $10 \%$ of the mould length.

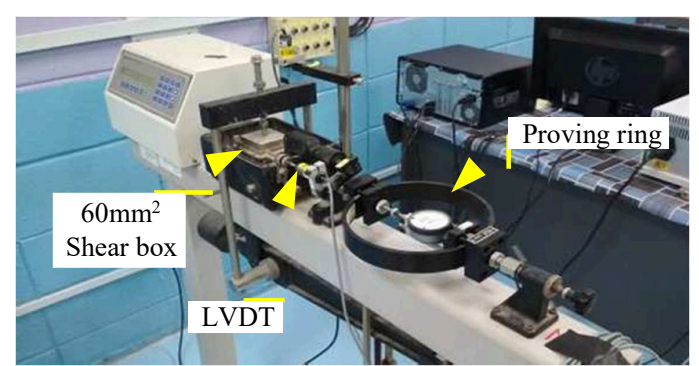

(a)

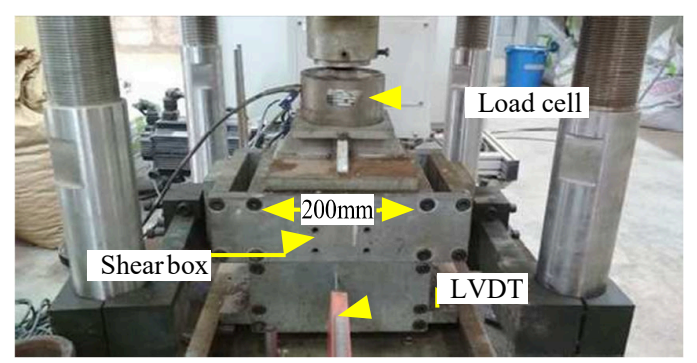

(b)

Fig. 2. (a) Apparatus for the SSDS test use a proving ring to measure the shear load and sample was placed in $60 \mathrm{~mm} \times 60 \mathrm{~mm}$ shear box (b) LSDS test uses a load cell to measure the shear load and sample was placed in $200 \mathrm{~mm} \times 200 \mathrm{~mm}$ steel box. Both of them use LVDT to measure the displacement in $\mathrm{mm}$.

\section{Results and Discussions}

The maximum shear stress $(\tau)$ of the SSDS and LSDS test where the failure occurs is presented in Table 3 to Table 5. Internal friction angle $(\varphi)$ and cohesion (c) value can be obtained according to Equation 1 from the maximum shear stress $(\tau)$ applied.

Table 3. Results of NCA and RCA with a size of $0.425 \mathrm{~mm}$ in SSDS test

\begin{tabular}{llccccc}
\hline No & $\begin{array}{c}\text { Sample } \\
\text { Type }\end{array}$ & $\begin{array}{c}\text { Normal } \\
\text { Force } \\
(\mathbf{k N})\end{array}$ & $\begin{array}{c}\text { Max. } \\
\text { Horizontal } \\
\text { Force } \\
(\mathbf{k N})\end{array}$ & $\begin{array}{c}\text { Plane } \\
\text { Area } \\
\mathbf{( m}^{2} \mathbf{)}\end{array}$ & $\begin{array}{c}\text { Normal } \\
\text { Stress, } \boldsymbol{\sigma} \\
\mathbf{( k P a )}\end{array}$ & $\begin{array}{c}\text { Shear } \\
\text { Stress, } \boldsymbol{\tau} \\
\mathbf{( k P a )}\end{array}$ \\
\hline 1 & NCA & 0.104 & 0.064 & 0.0036 & 28.90 & 17.90 \\
2 & NCA & 0.202 & 0.101 & 0.0036 & 56.10 & 28.10 \\
3 & NCA & 0.398 & 0.209 & 0.0036 & 110.60 & 58.10 \\
4 & RCA & 0.104 & 0.063 & 0.0036 & 28.90 & 17.60 \\
5 & RCA & 0.202 & 0.111 & 0.0036 & 56.10 & 30.70 \\
6 & RCA & 0.398 & 0.212 & 0.0036 & 110.60 & 58.80 \\
\hline
\end{tabular}


Table 4. Results of NCA and RCA with a size of $2.0 \mathrm{~mm}$ in SSDS test

\begin{tabular}{llccccc}
\hline No & $\begin{array}{c}\text { Sample } \\
\text { Type }\end{array}$ & $\begin{array}{c}\text { Normal } \\
\text { Force } \\
\mathbf{( k N )}\end{array}$ & $\begin{array}{c}\text { Max. } \\
\text { Horizontal } \\
\text { Force } \\
(\mathbf{k N})\end{array}$ & $\begin{array}{c}\text { Plane } \\
\text { Area } \\
\mathbf{( m}^{2} \mathbf{)}\end{array}$ & $\begin{array}{c}\text { Normal } \\
\text { Stress, } \boldsymbol{\sigma} \\
\mathbf{( k P a )}\end{array}$ & $\begin{array}{c}\text { Shear } \\
\text { Stress, } \boldsymbol{\tau} \\
\mathbf{( k P a )}\end{array}$ \\
\hline 1 & NCA & 0.104 & 0.063 & 0.0036 & 28.90 & 17.47 \\
2 & NCA & 0.202 & 0.126 & 0.0036 & 56.10 & 35.10 \\
3 & NCA & 0.398 & 0.231 & 0.0036 & 110.60 & 64.30 \\
4 & RCA & 0.104 & 0.058 & 0.0036 & 28.90 & 16.10 \\
5 & RCA & 0.202 & 0.139 & 0.0036 & 56.10 & 38.50 \\
6 & RCA & 0.398 & 0.218 & 0.0036 & 110.60 & 60.60 \\
\hline
\end{tabular}

Table 5. Results of NCA and RCA with specified gradation in LSDS test

\begin{tabular}{llccccc}
\hline No & $\begin{array}{c}\text { Sample } \\
\text { Type }\end{array}$ & $\begin{array}{c}\text { Normal } \\
\text { Force } \\
\mathbf{( k N )}\end{array}$ & $\begin{array}{c}\text { Max. } \\
\text { Horizontal } \\
\text { Force } \\
(\mathbf{k N})\end{array}$ & $\begin{array}{c}\text { Plane } \\
\text { Area } \\
\left(\mathbf{m}^{2} \mathbf{)}\right.\end{array}$ & $\begin{array}{c}\text { Normal } \\
\text { Stress, } \boldsymbol{\sigma} \\
\mathbf{( k P a )}\end{array}$ & $\begin{array}{c}\text { Shear } \\
\text { Stress, } \boldsymbol{\tau} \\
\mathbf{( k P a )}\end{array}$ \\
\hline 1 & NCA & 5.00 & 10.970 & 0.040 & 125.00 & 274.25 \\
2 & NCA & 10.00 & 17.420 & 0.040 & 250.00 & 435.50 \\
3 & NCA & 20.00 & 25.920 & 0.040 & 500.00 & 648.00 \\
4 & RCA & 5.00 & 11.850 & 0.040 & 125.00 & 296.25 \\
5 & RCA & 10.00 & 16.100 & 0.040 & 250.00 & 402.50 \\
6 & RCA & 20.00 & 20.220 & 0.040 & 500.00 & 505.50 \\
\hline
\end{tabular}

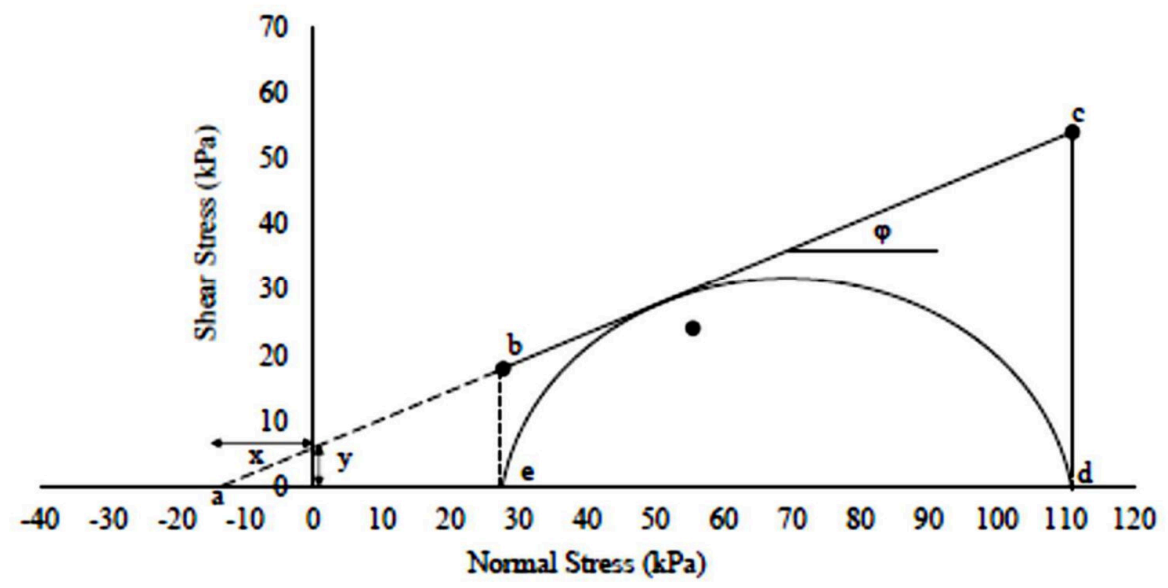

Fig. 3. Result for NCA with size $0.425 \mathrm{~mm}$ in Mohr-Coulomb chart

Result for NCA with a size of $0.425 \mathrm{~mm}$ can be drawn in the Mohr-Coulomb chart as shown in Fig. 3. The y in Fig. 3 represents the cohesion value as shown in Fig. 1 previously. By using the congruence triangle theory, y value can be calculated as follows:

Conditions are,

$$
\begin{aligned}
& a e=x+28.90 \\
& e b=17.90 \\
& a d=x+110.60 \\
& c d=58.10
\end{aligned}
$$


therefore,

$$
\begin{aligned}
\frac{x+28.90}{17.90} & =\frac{x+110.60}{58.10} \\
x & =7.48
\end{aligned}
$$

then,

$$
\begin{aligned}
\frac{7.48}{y} & =\frac{7.48+28.90}{17.90} \\
y & =3.68
\end{aligned}
$$

After the value of y is obtained which represents the cohesion value, then by using Eq. (1) the internal friction angle $(\varphi)$ can be obtained as follows:

$$
\begin{aligned}
& 17.90=3.68+(28.90 \times \tan \varphi) \\
& 14.22=28.90 \times \tan \varphi \\
& \tan \varphi=0.4920 \\
& \tan \varphi=26.20
\end{aligned}
$$

The same calculation for cohesion and internal friction angle also goes for all results from sample 2 until 6 and presented in Table 6 as follows:

Table 6. Internal friction angle and cohesion value

\begin{tabular}{clcc}
\hline No & Sample Type & $\begin{array}{c}\text { Cohesion, } \\
(\mathbf{k P a})\end{array}$ & $\begin{array}{c}\text { Internal friction } \\
\text { angle, } \boldsymbol{\varphi}\end{array}$ \\
\hline 1 & NCA 0.425 mm & 3.68 & 26.20 \\
2 & RCA 0.425 mm & 3.03 & 26.76 \\
3 & NCA 2.0 mm & 0.90 & 29.82 \\
4 & RCA 2.0 mm & 0.36 & 28.58 \\
5 & NCA in gradation & 149.67 & 44.90 \\
6 & RCA in gradation & 226.50 & 29.16 \\
\hline
\end{tabular}

The internal friction angle for RCA from three types of samples tend to sit at a similar value, whereas for NCA is rising as the grain becomes various and larger. The FHWA technical brief stated that the graded aggregate has various results for its internal friction angle but recommends the value of 39 degrees [14]. The value of the internal friction angle is subjective to the factors such as crushing strength, granular gradation, shape, particle size, sample water content, sample density and porosity [4]. In this research, the NCA and RCA for the graded sample have a flakiness index at $15.50 \%$ and $12.10 \%$ respectively. It means that the NCA can have a better interlocking action between the aggregates, thus it has a higher internal friction angle.

Results for the SSDS test show that at the size of $0.425 \mathrm{~mm}$, the peak shear strength between NCA and RCA does not have much difference. Whereas at the size of $2.0 \mathrm{~mm}, \mathrm{NCA}$ has a slightly higher peak shear strength compared to RCA as seen in Fig. 4. The difference of the peak shear strength can be proposed by the different density between the sample materials [15], which is clear enough for sample in the size of $2.0 \mathrm{~mm}$ and the specified gradation. The higher sample density, the higher its peak shear strength. But for sample in $0.425 \mathrm{~mm}$ size, it shows that NCA which has a slightly higher density than RCA, end up with a slightly lower peak shear strength. The results show that NCA and RCA in $0.425 \mathrm{~mm}$ size have a similar density and peak shear strength because of the difference is less than $5 \%$. However, further research must be conducted to obtain a more accurate result. 


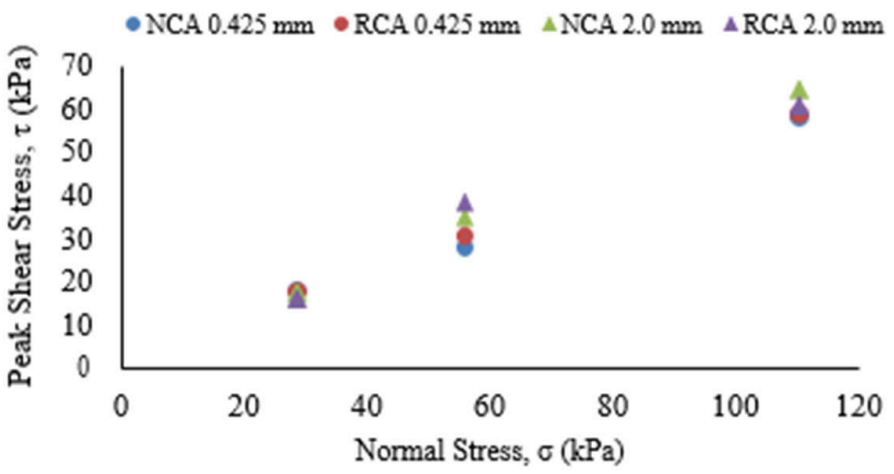

Fig. 4. Correlation of normal stress and peak shear stress in SSDS test

\section{Conclusions}

The internal friction angle of the NCA and RCA were similar at the size of coarse sand $(0.63$ $2.0 \mathrm{~mm})$ and medium sand $(0.20-0.63 \mathrm{~mm})$. Both NCA and RCA at these sizes show the internal friction angle at 26 to 29 degrees. While for the sample with the specified gradation, the internal friction angle showed a significant difference. The NCA had internal friction angle at 44.90 degrees whereas the RCA at 29.16 degrees. The internal friction angle and cohesion value not always show a linear correlation. The cohesion value is dependant to many factors such as material content, water content, bonding agents, etc. Thus, in construction planning, the cohesion value for granular soil is less considered and mostly assumed as zero. The shear strength of the tested materials also proved to be dependent on the internal tension and external stress. The shape of the grain also holds an important role in the material shear strength as it will become the main factor for the interlocking action between the material grains.

\section{Acknowledgements}

Sincere thanks to Universiti Teknologi Malaysia for financial support from High Impact Research Grant (HIR) Q.J130000.2451.04G54 that enabled the conduct of this research.

\section{References}

[1] Mathew, T.V. and Rao, K.V.K. (2007). Introduction to Transportation Engineering. Introduction to Transportation Engineering, National Programme on Technology Enhanced Learning (NPTEL), 03-08.

[2] Blaschke, B.C., Afferton, K.C. and Willett, T. (1993), AASHTO Guide For Design of Pavement Structures, Washington: AASHTO

[3] Mathew, T.V. and Rao, K.V.K. (2007). Introduction to Pavement Design. Introduction to Transportation Engineering, National Programme on Technology Enhanced Learning (NPTEL), 19.1-19.7.

[4] Xu, Y. (2019). In-situ Shear Strength of Compacted Demolition Waste. Powder Technol., vol. $352,72-78$.

[5] Taylor \& Francis Group. (2006). The Handbook of Highway Engineering, CRC Press.

[6] Vinod, B.R. (2011). Pavement Materials: Aggregates. Pavement Materials and Construction, Bangalore: BMS Institute of Technology and Management.

[7] Mathew, T.V. and Rao, K.V.K. (2007). Pavement Materials: Aggregates. Introduction to Transportation Engineering, National Programme on Technology Enhanced Learning (NPTEL), 01-08.

[8] JKR/SPJ/2008-S4. (2008). Standard Specification for Road Works - Section 4: Flexible Pavement. Jabatan Kerja Raya (JKR) Malaysia, 01-187.

[9] Allen, T. (2013). Engineering Properties of Soil and Rock. WSDOT Geotechnical Design 
Manual, no. October, Washington State Department of Transportation, 01-46.

[10] Obe, R.K.D., de Brito, J., Silva, R.V. and Lye, C.Q. (2019). Use of Recycled Aggregates in Geotechnical Applications. Sustainable Construction Materials: Recycled Aggregates, Elsevier Ltd., 419-450.

[11] BS 1377-7. (1990). Soils for Civil Engineering Purposes - Part 7: Shear Strength Tests (Total Stress), vol. 3, no. 1. British Standard Institution.

[12] BS 1377-1. (2016). Methods of Test for Soils For Civil Engineering Purposes - Part 1: General Requirements and Sample Preparation, no. 1. British Standard Institution.

[13] Giwangkara, G.G., Mohamed, A., Nor, H.Mohd. and Khalid, N.H.A. (2019). Recycled Concrete Aggregate as a Road Base Material. Geotropika and Ichitra 2019.

[14] Nicks, J. (2013). Friction Angles Of Open- Graded Aggregates From Large-Scale Direct Shear Testing. FWHA Technical Brief, FHWA-HRT-13-068, United States: Department of Transportation.

[15] Mahony, M.O. (1997). An Analysis of the Shear Strength of Recycled Aggregates. Journal of Materials and Structures, vol. 1, 01-15. 